\title{
Low prevalence of iron-deficiency anaemia among Invit preschool children: Nunavut Inuit Child Health Survey, 2007-2008
}

\author{
Angela Pacey, Hope Weiler and Grace M Egeland* \\ Centre for Indigenous Peoples' Nutrition and Environment, MacDonald Campus, School of Dietetics and \\ Human Nutrition, McGill University, Saint-Anne-de-Bellevue, QC, H9X 3V9, Canada
}

Submitted 23 January 2010: Accepted 16 July 2010: First published online 5 0ctober 2010

\begin{abstract}
Objective: To report the prevalence rates and correlates for anaemia, iron deficiency (ID) and iron-deficiency anaemia (IDA) among Inuit preschool-aged children. Design: A cross-sectional study assessed iron intake, demographic information, medical history, anthropometrics, $\mathrm{Hb}$, ferritin, C-reactive protein and antibodies to Helicobacter pylori.

Setting: Sixteen selected Inuit communities in Nunavut Territory, Canada.

Subjects: Inuit ( $n$ 388) aged 3-5 years randomly recruited from communities.

Results: Anaemia (3-4 years: $\mathrm{Hb}<110 \mathrm{~g} / 1 ; 5$ years: $\mathrm{Hb}<115 \mathrm{~g} / \mathrm{l})$ was prevalent in $16 \cdot 8 \%$ of children. The prevalence of ID (ferritin $<12 \mu \mathrm{g} / \mathrm{l}$ ) was $18 \cdot 0 \%$ and that of IDA was $5 \cdot 4 \%$. When ID was defined as ferritin $<10 \mu \mathrm{g} / 1,10 \cdot 8 \%$ of children were iron deficient and $3 \cdot 3 \%$ had IDA. In multiple logistic regression, boys were more likely to be iron deficient $(\mathrm{OR}=2 \cdot 28,95 \% \mathrm{CI} 1 \cdot 17,8 \cdot 25)$, but no other risk factor emerged for ID. Three- to 4-year-olds were less likely than 5-year-olds to have anaemia from causes other than ID (OR $=0 \cdot 11,95 \%$ CI 0 08, 0.58). Anaemia from other causes was more common among children residing in crowded homes $(\mathrm{OR}=2 \cdot 30,95 \% \mathrm{CI} 1 \cdot 37,12 \cdot 31)$ and those treated for past-year ear infection $(\mathrm{OR}=1 \cdot 35,95 \%$ CI $1 \cdot 05,7 \cdot 21)$.

Conclusions: The low prevalence of ID and IDA is encouraging, but efforts are still needed to reduce rates as they continue to be higher than general population rates. Household crowding and infections may contribute to anaemia and warrant further research.
\end{abstract}

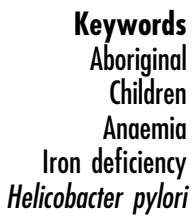

In infants and children, iron-deficiency anaemia (IDA) can have serious health consequences including impaired growth and cognitive development and weakened immune defence ${ }^{(1-3)}$. Iron deficiency (ID) typically exists in three stages: low iron stores, reduced iron delivery to the tissues and IDA characterized by low $\mathrm{Hb}$ and reduced erythrocyte size ${ }^{(4)}$. The aboriginal people of Canada include three distinct groups: Inuit, First Nations and Métis ${ }^{(5)}$, and there is evidence that the rates of anaemia and ID are higher among aboriginal children than among non-aboriginal children. Recent prevalence estimates for Inuit infants are 36-60\% for ID compared with $33 \%$ for non-aboriginal Canadian infants ${ }^{(6-8)}$. IDA is thought to affect $26 \%$ of Inuit infants compared with $5 \%$ for non-aboriginal infants ${ }^{(6-8)}$. Information for the preschool age group of $3-5$ years is lacking. Prevalence estimates for Canadian infants and children combined are $24 \%$ for tissue ID and 5\% for anaemia from all causes ${ }^{(9)}$. Current information on ID and IDA among Canadian Inuit preschoolers, however, is not available.
Studies among Inuit children show that dietary iron intake is most likely adequate ${ }^{(6,10-12)}$. However, a nutrition transition in the Arctic is rapidly occurring, which warrants ongoing nutritional status assessment and biomarker monitoring. Further, infection with the human pathogen, Helicobacter pylori, has been postulated to contribute to ID, although the mechanisms remain unclear $^{(13-23)}$. H. pylori infection is highly prevalent in Arctic populations ${ }^{(6,24,25)}$ and may increase the risk for ID among Inuit children ${ }^{(16)}$. Therefore, a cross-sectional survey of Inuit preschool children in Nunavut was used to evaluate the prevalence and correlates of anaemia, ID and IDA. The study to date has identified a high prevalence of child food insecurity (56\%) as well as of other indicators of socio-economic disadvantage including household crowding (53.9\%), income support (42.7\%) and living in public housing $(69 \cdot 7 \%)^{(26)}$. The children are of normal stature $^{(27)}$, but have a high prevalence of overweight based upon Centers for Disease Control and Prevention $(\mathrm{CDC})^{(27)}$ and WHO international standards ${ }^{(26)}$. Further, 
nearly half of the children consumed traditional Inuit food in the past $24 \mathrm{~h}$ and traditional food contributed to nutrient intakes, including iron ${ }^{(28)}$.

\section{Experimental methods}

\section{Setting}

This research is part of the Inuit Child Health Survey of preschool children in the Nunavut Territory of Canada, with details of the study design and demographic characteristics described elsewhere ${ }^{(26,28)}$. Using currently available population census information, we estimated that a sample of ninety to 100 children would provide $90 \%$ power to detect a population prevalence of IDA of 10 (SD 5) \%. A sample size of 300 was then desired as a minimum to allow for multivariable analyses and assessment of other correlates. Sixteen of the twenty-five communities in Nunavut were chosen to participate. The communities were selected to represent the three jurisdictional regions within Nunavut, to be geographically dispersed by latitude, and to represent small, middle and large-size communities. From these communities, Inuit children, aged 3-5 years, were randomly selected to participate in the survey using health centre lists of age-appropriate children. Recruiters were instructed to make three attempts to reach caregivers. Written informed consent was obtained from the children's caregivers. The survey was developed by a steering committee consisting of partners from Inuit and community organizations, Nunavut health officials and McGill University and the University of Toronto. Certification of ethical acceptability for research involving human subjects was obtained from the McGill Faculty of Medicine Institutional Review Board. A scientific research licence was obtained from the Nunavut Research Institute.

\section{Antbropometry}

For the current report, age- and sex-appropriate BMI $Z$-scores were based upon the 2000 CDC growth reference ${ }^{(29)}$.

\section{Iron status and exposure to $\mathrm{H}$. pylori}

Venous or capillary sampling was used to obtain blood samples. When venepuncture was used, $3 \mathrm{ml}$ of blood was collected into sodium heparin Vacutainer ${ }^{\circledR}$ blood tubes (Becton Dickinson, Franklin Lakes, NJ, USA). The Vacutainer tube was inverted gently ten times. One drop of whole blood was dispensed onto Parafilm (Pechiney, Chicago, IL, USA) using a Diff-Safe ${ }^{\circledR}$ blood dispenser (Alpha Scientific Corporation, Southeastern PA, USA). Hb was measured either from this drop or from capillary blood samples using the cyanmethaemoglobin method with a HemoCue $\mathrm{TM}^{\mathrm{TM}} 201+$ portable photometer (HemoCue Inc., Lake Forest, CA, USA). Blood samples were centrifuged within $6 \mathrm{~h}$ of collection. Separated plasma was stored at $-20^{\circ} \mathrm{C}$ during fieldwork and at $-80^{\circ} \mathrm{C}$ after completion of data collection.
Ferritin was measured from plasma samples using an autoanalyser (Liason ${ }^{\circledR}$; DiaSorin, Saluggia, Italy) and a ferritin integral (REF 313551, DiaSorin, Saluggia, Italy). Low, normal and high control samples were tested with each analysis. C-reactive protein (CRP) was measured using a SYNCHRON ${ }^{\circledR}$ autoanalyser (Beckman Coulter, Inc., Brea, CA, USA) and a high-sensitivity CRP (hsCRP) assay at the Montréal Children's General Hospital, Montréal, Canada. Previous exposure to H. pylori was assessed using a qualitative ELISA (Pylori Detect IgG; Calbiotech, Spring Valley, CA, USA) for the presence of anti-H. pylori IgG antibodies in plasma. Logistical aspects of conducting carbon urea breath tests given the other research priorities precluded assessment of current $H$. pylori infection.

ID was defined as low ferritin $(<12 \mu \mathrm{g} /)^{(2)}$. IDA was defined as the presence of low ferritin coupled with low $\mathrm{Hb}$. Other anaemia was defined as low $\mathrm{Hb}$, but normal ferritin $(\geq 12 \mu \mathrm{g} / 1)$. As the cut-off value for low ferritin in children is currently unclear, we also conducted analyses using ferritin $<10 \mu \mathrm{g} / 1$ to define ID and $\operatorname{IDA}^{(8,30)}$. The presence of acute inflammation elevates circulating ferritin concentrations; therefore, prevalence estimates for ID and IDA were restricted to children in whom hsCRP was below $8 \mathrm{ng} / \mathrm{ml}^{(7)}$. Analyses were also repeated using a lower hsCRP cut-off of $3 \mathrm{ng} / \mathrm{ml}^{(31,32)}$, but as no differences were identified, only results using the $8 \mathrm{ng} / \mathrm{ml}$ cut-off are presented.

\section{Dietary intake}

A $24 \mathrm{~h}$ dietary recall was conducted for each child participant with a non-consecutive day repeat recall conducted for a $20 \%$ subsample. Interviewers were trained using a fivestage, multiple-pass interviewing technique. Food model kits were used to estimate portion sizes. Interviewers were asked about the child's mineral and vitamin supplement use, including frequency and brand information to allow for determination of nutrient content. Each caregiver was asked to complete a past-month qualitative FFQ for their child on traditional Inuit foods and market foods high in iron. Food frequency information was entered using EpiInfo (CDC, Atlanta, GA, USA). The $24 \mathrm{~h}$ dietary recall information was entered using CANDAT (Godin London Incorporated, London, Ontario, Canada). Iron intake was obtained using the Canadian Nutrient File (Health Canada 2007) and a database of 2000 additional foods derived from standardized recipes and food labels. All dietary data entries were double verified for errors. Traditional food intake used in univariate analyses was dichotomized based on a frequency of consumption that was greater or less than the median.

\section{The bome environment}

Interviewers conducted questionnaires for characteristics of the home including the United States Department of Agriculture's eighteen-item Household Food Security Survey Module adapted for the Inuit populations ${ }^{(33,34)}$. The food security module was scored according to Health 
Canada guidelines and detailed methods and findings are described elsewhere ${ }^{(26)}$. Household crowding was defined as living in a home with greater than the median number of people per household.

\section{Statistical analyses}

There was incomplete ascertainment of all variables for all children. Univariate statistical analyses were conducted using all available data (H. pylori, $n$ 282; hsCRP, $n$ 254; Hb, $n$ 285; ferritin, $n$ 253; iron intake, $n$ 374). Weighted prevalence rates with $95 \%$ CI for anaemia, IDA and ID were estimated. Sampling weights were based on the proportion of participating children in each community using the total number of age-appropriate children obtained from health centre lists as the denominator for calculating weights.

Usual iron intake from the $24 \mathrm{~h}$ recall was estimated from observed intake using Software for Intake Distribution Estimation (Iowa State University, 1996). Adjustments were made for sequence and day of week of the recall. Within-person variability was estimated using information from the $20 \%$ subsample of repeat recalls. The percentage of children below the age-appropriate Estimated Average Requirement (EAR) for iron was determined ${ }^{(35)}$. The frequency of consumption of iron-containing traditional and market food was calculated, both for consumers only and for all children. The three outcomes of interest were ID, IDA and other anaemia. Univariate analyses of outcome and exposure variables were performed using a $\chi^{2}$ test or Fisher's exact test when cell sizes were $<10$. Relative risks (RR) and 95\% CI were calculated for relevant exposure variables. As sex differences were noted in ID, a post hoc $t$ test examined sex differences in dietary iron intake. Multivariable logistic regression was performed to examine independent effects of exposure variables when variables were of borderline significance $(P<0 \cdot 10)$ in univariate analyses; adjusted OR were calculated from regression coefficients. For all analyses, a $P$ value $<0.05$ was considered significant. Weighted prevalence rates and dietary adequacy analyses were determined using the SAS statistical software package version 9.1 (SAS Institute, Cary, NC, USA). All other analyses were performed using the STATA statistical software package version $10 \cdot 0$ (StataCorp., College Station, TX, USA).

Differences in $\mathrm{Hb}$ levels obtained from capillary and venous blood samples were evaluated to determine the feasibility of combining the data in an overall assessment of anaemia prevalence. Mean Hb concentration in capillary blood samples (114 (SD 12) g/l) was significantly lower than that in venous blood samples (118 (SD 7) g/l, Wilcoxon rank $P<0 \cdot 01$ ), perhaps attributed to a dilution effect associated with finger prick sampling. There were, however, no socio-economic differences noted between those who provided a capillary or a venous blood sample, which suggested that anaemia prevalence rates would not be biased by excluding capillary blood samples from the analyses. Thus, analyses involving the Hb reported herein were based solely upon venous blood samples.

\section{Results}

Of the 644 homes approached, a total of 537 homes were successfully contacted, of whom seventy-five (11.6\%) refused upon initial contact and seventy-four (13.8\%) cancelled or did not attend their clinic appointment. The overall participation rate was $72 \cdot 3 \%$ ( $n$ 388). Venous blood was obtained from 289 of 388 children $(74 \cdot 7 \%)$ and capillary blood samples from seventy-nine of 388 children $(20 \cdot 4 \%)$. Five per cent of the children did not undergo any blood sampling.

\section{Population characteristics}

Fifty-three per cent of the participating children were female and the mean age was $4 \cdot 4$ (SD 0.9) years. Daycare was attended by $38.3 \%$ of children. Sixteen per cent of caregivers reported that they gave their children a nutritional supplement containing iron, most commonly multi-vitamin and mineral supplements. The weighted prevalence of exposure to $H$. pylori was high at $46 \cdot 1 \%$ (95\% CI 40.1, 52.1; Table 1). The median hsCRP concentration was $0.65 \mathrm{ng} / \mathrm{ml}$ (25th percentile: $0 \cdot 2 \mathrm{ng} / \mathrm{ml}$; 75 th percentile: $2 \cdot 2 \mathrm{ng} / \mathrm{ml}$ ). Overall, fourteen children $(5 \cdot 1 \% ; 95 \%$ CI $2 \cdot 2,8 \cdot 0)$ had high hsCRP concentrations of $\geq 8 \mathrm{ng} / \mathrm{ml}$. These children, along with twenty-one children whose hsCRP status could not be determined, were excluded in determining the prevalence of ID and IDA as well as from univariate and multivariate analyses.

\section{Prevalence of iron deficiency and anaemia}

The mean ferritin concentration was $19 \cdot 1$ (SD 10·1) $\mu \mathrm{g} / \mathrm{l}$ and the median was $16 \cdot 6 \mu \mathrm{g} / \mathrm{l}$ (Fig. 1a). Overall, 18.0\% (95\% CI $12 \cdot 7,23 \cdot 3)$ of children were iron deficient using a ferritin cut-off of $12 \mu \mathrm{g} / \mathrm{l}$ (Table 1 ). Using a ferritin cut-off of $10 \mu \mathrm{g} / \mathrm{l}$, the prevalence of ID decreased to $10 \cdot 9 \%(95 \% \mathrm{CI} 6 \cdot 5,15 \cdot 2$; Table 1). IDA was found in $5 \cdot 4 \%(95 \%$ CI $2 \cdot 3,8 \cdot 6)$ of

Table 1 Prevalence of ID, anaemia, IDA and Helicobacter pylori infection among participating children: Nunavut Inuit Child Health Survey, 2007-2008

\begin{tabular}{lccc}
\hline & $n / N$ & Prevalence (\%) & $95 \% \mathrm{Cl}$ \\
\hline Ferritin $(<12 \mu \mathrm{g} / \mathrm{l})$ & & & \\
ID & $45 / 238$ & $18 \cdot 0$ & $12 \cdot 7,23 \cdot 3$ \\
$\quad$ IDAt & $11 / 235$ & $5 \cdot 4$ & $2 \cdot 3,8 \cdot 6$ \\
Ferritin $(<10 \mu \mathrm{g} / \mathrm{l})$ & & & \\
ID & $25 / 238$ & $10 \cdot 8$ & $6 \cdot 5,15 \cdot 2$ \\
$\quad$ IDAt & $7 / 235$ & $3 \cdot 3$ & $0 \cdot 9,5 \cdot 8$ \\
Anaemiał & $47 / 285$ & $16 \cdot 8$ & $12 \cdot 0,21 \cdot 6$ \\
H. pylori infection & $128 / 282$ & $46 \cdot 1$ & $40 \cdot 1,52 \cdot 1$ \\
\hline
\end{tabular}

ID, iron deficiency; IDA, iron-deficiency anaemia. tPresence of anaemia coupled with ID.

$\ddagger \mathrm{Hb}<110 \mathrm{~g} / \mathrm{l}$ (in 3-4-year-olds) or $<115 \mathrm{~g} / \mathrm{l}$ (in 5-year-olds). 

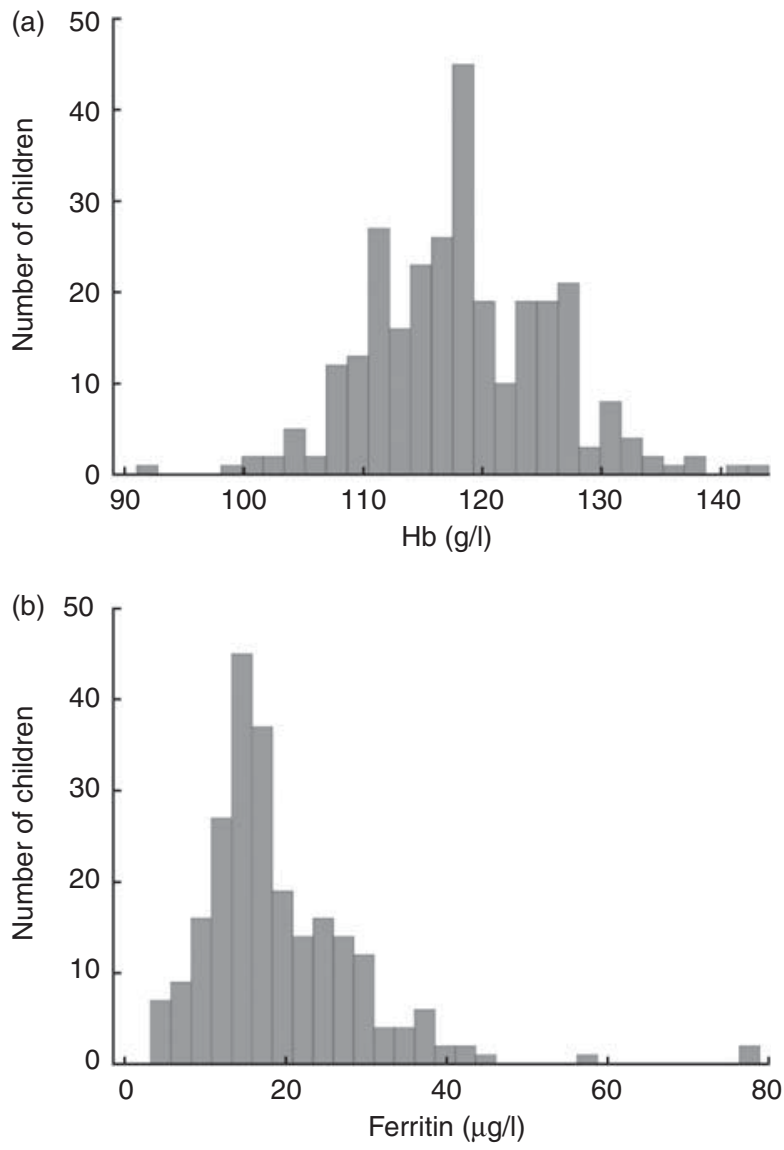

Fig. 1 (a) Distribution of $\mathrm{Hb}$ concentration values among Inuit preschoolers, where anaemia is defined as $\mathrm{Hb}$ below $110 \mathrm{~g} / \mathrm{l}$ (3-4-year-olds) or $115 \mathrm{~g} / \mathrm{l}$ (5-year-olds). (b) Distribution of ferritin concentration values among Inuit preschoolers, where ferritin below 10 or $12 \mu \mathrm{g} / \mathrm{l}$ is defined as iron deficiency in children (Nunavut Inuit Child Health Survey, 2007-2008)

children and when the lower ferritin cut-off was used, the prevalence of IDA decreased to $3 \cdot 3 \%(95 \%$ CI $0 \cdot 9,5 \cdot 8)$.

The mean $\mathrm{Hb}$ concentration was $118 \mathrm{~g} / 1$ (sD 8·0; Fig. 1b). The weighted prevalence of anaemia from all causes was $16 \cdot 8 \%(95 \%$ CI 12·0, 21·6). Among children with anaemia, $4 \cdot 3 \%$ had moderate-to-severe anaemia $(\mathrm{Hb}<100 \mathrm{~g} / \mathrm{l})$, whereas $95 \cdot 7 \%$ had mild anaemia $(\mathrm{Hb} \geq 100 \mathrm{~g} / \mathrm{l}$, but below age-specific cut-off). ID (ferritin $<12 \mu \mathrm{g} / \mathrm{l}$ ) explained $31 \%$ of observed anaemia. When ID was defined as ferritin below $10 \mu \mathrm{g} / \mathrm{l}$, it explained $20 \%$ of the observed anaemia. Thus, $69-80 \%$ of the anaemia observed in Inuit preschoolers was most likely due to causes other than low iron stores.

\section{Dietary iron intake}

Iron intake was normally distributed with a mean of 15.6 (sD $11 \cdot 0) \mathrm{mg} / \mathrm{d}$ and median of $13.5 \mathrm{mg} / \mathrm{d}$. Only $0.3 \%$ of children had iron intake below their age-specific EAR (1-3 years: $3.0 \mathrm{mg} / \mathrm{d}$; $4-8$ years: $4 \cdot 1 \mathrm{mg} / \mathrm{d}$ ). Based on the FFQ, children commonly consumed various iron-rich foods such as caribou meat $(84 \cdot 2 \%)$, ringed seal meat $(49 \cdot 5 \%)$, beef (82.6\%) and breakfast cereals (96.3\%; Table 2$)$.

\section{Correlates of iron deficiency and iron-deficiency anaemia}

In univariate and multivariate logistic regressions, no significant correlates emerged for ID or for IDA when using the ferritin cut-off value of $12 \mu \mathrm{g} / \mathrm{l}$. However, when using the lower ferritin cut-off value $(10 \mu \mathrm{g} / 1)$, age and sex were significantly associated with ID (Table 3 ) but not with IDA (data not presented given the small number of IDA events). In univariate analyses, boys were more likely to be iron deficient than girls $(\mathrm{RR}=3 \cdot 22,95 \% \mathrm{CI}$ $1 \cdot 33,7 \cdot 78)$, and children aged $3-4$ years were more likely to be iron deficient than 5-year-olds $(\mathrm{RR}=3 \cdot 31,95 \%$ $1 \cdot 02,10 \cdot 71)$. In a multiple logistic regression model for ID containing age, sex and BMI $Z$-scores, only boys were significantly at risk (adjusted OR $=2 \cdot 28,95 \%$ CI $1 \cdot 17$, $8 \cdot 25)$. However, there were no significant differences in mean dietary iron intakes between boys (15.5 (SD $5 \cdot 8) \mathrm{mg} / \mathrm{d})$ and girls $(15 \cdot 6(\mathrm{sD} 6 \cdot 1) \mathrm{mg} / \mathrm{d})$.

\section{Correlates of otber anaemia}

Correlates for anaemia from causes other than ID were examined (Table 3). Three- to 4-year-olds were less likely to be anaemic from other causes (5.3\%) than 5-year-olds (19.2\%; RR $=0 \cdot 28,95 \%$ CI $0 \cdot 13,0 \cdot 60)$. Children residing in a home with six or more individuals were more likely to be anaemic (12.3\%) than those living in less crowded homes $(4 \cdot 8 \%$; RR $=2 \cdot 56,95 \% \mathrm{CI} 1 \cdot 04,6 \cdot 34)$. Children who were treated for an ear infection in the past 12 months were more likely to be anaemic (14.5\%) than children not requiring treatment for an ear infection $(6 \cdot 6 \%$; $\mathrm{RR}=2 \cdot 20$, $95 \%$ CI $1 \cdot 01,4 \cdot 76)$. There were no differences in mean BMI $Z$-scores or in hsCRP concentrations between children with and without anaemia from other causes. In a multiple logistic regression model adjusted for BMI $Z$-scores and sex, 3-4-year-olds were less likely to be anaemic relative to 5 -year-olds $(\mathrm{OR}=0 \cdot 11,95 \% \mathrm{CI} 0 \cdot 08,0 \cdot 58)$, while household crowding (OR $=2 \cdot 30,95 \%$ CI $1 \cdot 37,12 \cdot 31)$ and pastyear treatment for an ear infection $(\mathrm{OR}=1 \cdot 35,95 \%$ CI $1 \cdot 05$, $7 \cdot 21$ ) were associated with a significantly elevated risk for having anaemia from other causes.

\section{Discussion}

The present study is the first to report population-level prevalence estimates of ID and IDA for Inuit preschoolers in the Nunavut Territory, Canada. National prevalence estimates for Canadian preschoolers are currently not available. However, in comparison with American preschoolers, Inuit preschoolers have a higher prevalence of ID and IDA. In the USA, ID affects $4.5 \%$ of children aged $3-5$ years and IDA is found among $0.5 \%{ }^{(19)}$, whereas in the present study $10 \cdot 8-18 \cdot 0 \%$ were iron deficient and $3 \cdot 3-5 \cdot 4 \%$ had IDA, depending upon the cut-offs used. Natives of Alaska ${ }^{(16)}$ as well as Canadian Inuit infants $(6,7,9)$ have been observed to have higher rates of ID than the 
Table 2 Frequency of consumption of traditional and market food sources of iron among Inuit children aged 3-5 years: Nunavut Inuit Child Health Survey, 2007-2008

\begin{tabular}{|c|c|c|c|c|}
\hline & \multicolumn{2}{|c|}{$\begin{array}{l}\text { Percentage of } 3-5 \text {-year-olds } \\
\text { who consumed the food in the past month }\end{array}$} & \multicolumn{2}{|c|}{$\begin{array}{l}\text { Average number of days } \\
\text { consumed in a month }\end{array}$} \\
\hline & $\%$ & $n / N$ & Consumers only & All children \\
\hline \multicolumn{5}{|l|}{ Traditional foods } \\
\hline Caribou meat (dried, cooked, raw) & $84 \cdot 2$ & $320 / 380$ & $11 \cdot 8$ & $10 \cdot 0$ \\
\hline Fish, all types & $65 \cdot 3$ & $248 / 380$ & $7 \cdot 1$ & $4 \cdot 6$ \\
\hline Ringed seal meat & $49 \cdot 5$ & $188 / 380$ & $4 \cdot 3$ & $2 \cdot 2$ \\
\hline Clams/mussels from the land & $15 \cdot 5$ & $59 / 380$ & $3 \cdot 2$ & 0.5 \\
\hline Goose & $14 \cdot 7$ & $45 / 307 \dagger$ & $2 \cdot 9$ & $0 \cdot 4$ \\
\hline Ringed seal liver & $11 \cdot 6$ & $44 / 380$ & $3 \cdot 8$ & $0 \cdot 4$ \\
\hline Duck, all types & $10 \cdot 8$ & $41 / 380$ & $2 \cdot 2$ & $0 \cdot 2$ \\
\hline Walrus meat & $8 \cdot 6$ & 29/336t & $2 \cdot 0$ & $0 \cdot 2$ \\
\hline Musk-ox meat & $6 \cdot 0$ & $8 / 133+$ & $1 \cdot 7$ & $0 \cdot 1$ \\
\hline Caribou liver & $5 \cdot 0$ & $19 / 380$ & $5 \cdot 4$ & $0 \cdot 3$ \\
\hline Beluga meat & 4.5 & $17 / 380$ & $2 \cdot 5$ & $0 \cdot 1$ \\
\hline Ptarmigan and spruce hen & $3 \cdot 7$ & $14 / 380$ & $2 \cdot 3$ & $0 \cdot 1$ \\
\hline Narwhal meat & $2 \cdot 9$ & $11 / 380$ & $6 \cdot 0$ & $0 \cdot 2$ \\
\hline \multicolumn{5}{|l|}{ Market foods } \\
\hline Cereal, all types & $96 \cdot 3$ & $366 / 380$ & $28 \cdot 9$ & $27 \cdot 8$ \\
\hline Beef, all types & $82 \cdot 9$ & $315 / 380$ & $10 \cdot 4$ & $8 \cdot 5$ \\
\hline Poultry, all types & $82 \cdot 6$ & $314 / 380$ & 8.5 & $7 \cdot 0$ \\
\hline Pork, all types & $69 \cdot 7$ & $265 / 380$ & $8 \cdot 0$ & $5 \cdot 6$ \\
\hline
\end{tabular}

tOwing to the limited geographical availability of this food, $N$ is reduced because certain communities were not asked about this traditional food item.

general population ${ }^{(6,19)}$. The prevalence rates determined from the present study would most likely be defined as mild according to WHO thresholds for population-level $\mathrm{ID}^{(36)}$. However, improvements in iron status are possible given that rates of deficiency continue to be higher among Inuit preschoolers compared with preschoolers of the general US population.

Iron intake in this population is most likely adequate as only $0.3 \%$ of children had intake below the EAR. In addition, breakfast cereals, many of which are ironfortified, and beef and caribou were frequently consumed in this population. Among the same study population, only $0 \cdot 1 \%$ had intake below the EAR for vitamin $C^{(28)}$, suggesting that low iron bioavailability due to low vitamin $\mathrm{C}$ intake is unlikely. While over-reporting of portion sizes on $24 \mathrm{~h}$ dietary recalls is possible, the energy intake reported in the present study is similar to that observed in the Canadian Community Health Survey ${ }^{(37)}$. Dietary iron intake levels are also similar in the present study in comparison with others in Inuit, Métis and American children ${ }^{(11,12,38,39)}$.

The finding that more boys than girls were iron deficient is difficult to explain since there are no sex differences in iron requirements in the preschool age group. It has recently been shown that obesity and being overweight are associated with greater risk of ID, perhaps due to low diet quality, increased iron requirement due to higher blood volume as well as decreased iron absorption induced by chronic low-grade inflammation ${ }^{(40-44)}$. In another analysis of the Inuit Child Health Survey, boys were noted to have higher BMI-for-age $Z$-scores than girls ${ }^{(27)}$. However, we found no significant associations between ID and BMI $Z$-scores, and BMI $Z$-scores did not alter the relationship between sex and ID in logistic regression. It is possible that the association between BMI $Z$-scores and ID is relevant to Inuit preschoolers, but our study was not powered to detect this perhaps weak or moderate association.

In addition, the present study used a $24 \mathrm{~h}$ dietary recall and a $20 \%$ random subsample repeat recall, which does not provide enough information to estimate nutrient intake for individuals. As such, nutritional ID or anaemia cannot be ruled out. However, since meat and dietary iron intake was high in the population overall, nutritional causes are unlikely to explain the observed ID and anaemia found among preschoolers.

The $45.4 \%$ prevalence of $H$. pylori exposure observed in the present study is high and consistent with other studies of Canadian First Nations and Inuit and Alaskan native children ${ }^{(6,16,24,25,45)}$. In contrast, lower rates of H. pylori exposure have been reported $(5 \cdot 5-7 \cdot 1 \%)$ for American and Canadian children ${ }^{(19,46)}$. We found no association between ID and $H$. pylori exposure among Inuit preschoolers. The present study is limited in that H. pylori infection assessment was related to previous exposure $^{(47-49)}$, thereby precluding comparisons with studies evaluating current infection. However, in various epidemiological studies and case reports in which H. pylori was shown to be independently associated with iron status, the association emerged primarily among older children ${ }^{(16,19,20-23,50)}$. For example, among the natives of Alaska, $H$. pylori was independently associated with ID for children aged 9 years and above, but not in younger age groups ${ }^{(16)}$. A causal relationship between H. pylori and iron status has yet to be established, but 
Table 3 Univariate analyses for correlates of iron deficiency (ferritin $<10 \mu \mathrm{g} /$ ) and anaemia from other causes: Nunavut Inuit Child Health Survey, 2007-2008

\begin{tabular}{|c|c|c|c|c|c|c|c|c|}
\hline & \multicolumn{4}{|c|}{ Iron deficiency } & \multicolumn{4}{|c|}{ Other anaemia } \\
\hline & $\%$ & $n / N$ & $\mathrm{RR}$ & $95 \% \mathrm{Cl}$ & $\%$ & $n / N$ & $\mathrm{RR}$ & $95 \% \mathrm{Cl}$ \\
\hline \multicolumn{9}{|l|}{ Age group (years) } \\
\hline $\begin{array}{l}3-4 \\
5\end{array}$ & $\begin{array}{r}13 \cdot 1 \\
4 \cdot 1\end{array}$ & $\begin{array}{c}22 / 164 \\
3 / 74\end{array}$ & $3 \cdot 31$ & $1 \cdot 02,10 \cdot 71^{*}$ & $\begin{array}{r}5.3 \\
19.2\end{array}$ & $\begin{array}{l}10 / 189 \\
14 / 73\end{array}$ & $0 \cdot 28$ & $0.13,0.60^{* \star *}$ \\
\hline \multicolumn{9}{|l|}{ Sex } \\
\hline Male & $16 \cdot 1$ & $19 / 118$ & $3 \cdot 22$ & $1 \cdot 33,7 \cdot 78^{\star}$ & $6 \cdot 5$ & $8 / 123$ & $1 \cdot 77$ & $0.79,3.99$ \\
\hline \multicolumn{9}{|c|}{ Helicobacter pylori exposure } \\
\hline $\begin{array}{l}\text { Positive } \\
\text { Negative }\end{array}$ & $\begin{array}{r}7 \cdot 8 \\
13 \cdot 1\end{array}$ & $\begin{array}{r}8 / 102 \\
17 / 130\end{array}$ & 0.60 & $0 \cdot 27,1 \cdot 33$ & $\begin{array}{r}8 \cdot 4 \\
10 \cdot 3\end{array}$ & $\begin{array}{l}10 / 119 \\
14 / 136\end{array}$ & $0 \cdot 82$ & $0 \cdot 38,1 \cdot 77$ \\
\hline \multicolumn{9}{|l|}{ Household size } \\
\hline $\begin{array}{l}\geq 6 \\
<6\end{array}$ & $\begin{array}{r}11 \cdot 3 \\
9 \cdot 5\end{array}$ & $\begin{array}{l}13 / 115 \\
11 / 116\end{array}$ & $1 \cdot 19$ & $0.56,2.55$ & $\begin{array}{r}12 \cdot 3 \\
4 \cdot 8\end{array}$ & $\begin{array}{r}16 / 130 \\
6 / 125\end{array}$ & $2 \cdot 56$ & $1 \cdot 04,6 \cdot 34^{\star}$ \\
\hline \multicolumn{9}{|l|}{ Child food insecurity } \\
\hline $\begin{array}{l}\text { Yes } \\
\text { No }\end{array}$ & $\begin{array}{r}9 \cdot 4 \\
12 \cdot 2\end{array}$ & $\begin{array}{l}12 / 128 \\
12 / 98\end{array}$ & 0.77 & $0.36,1.63$ & $\begin{array}{l}9 \cdot 1 \\
7 \cdot 4\end{array}$ & $\begin{array}{r}13 / 143 \\
8 / 108\end{array}$ & $1 \cdot 23$ & $0 \cdot 53,2 \cdot 86$ \\
\hline \multicolumn{9}{|l|}{ Iron supplement } \\
\hline $\begin{array}{l}\text { Yes } \\
\text { No }\end{array}$ & $\begin{array}{r}8 \cdot 6 \\
10 \cdot 8\end{array}$ & $\begin{array}{c}3 / 35 \\
21 / 195\end{array}$ & $0 \cdot 80$ & $0 \cdot 25,2 \cdot 53$ & $\begin{array}{l}9 \cdot 5 \\
8 \cdot 5\end{array}$ & $\begin{array}{c}4 / 42 \\
18 / 213\end{array}$ & $1 \cdot 13$ & $0 \cdot 40,3 \cdot 16$ \\
\hline \multicolumn{9}{|l|}{ Attends daycare } \\
\hline $\begin{array}{l}\text { No } \\
\text { Yes }\end{array}$ & $\begin{array}{r}13 \cdot 0 \\
6 \cdot 3\end{array}$ & $\begin{array}{c}18 / 138 \\
6 / 96\end{array}$ & 0.48 & $0 \cdot 20,1 \cdot 16$ & $\begin{array}{r}10 \cdot 3 \\
7 \cdot 8\end{array}$ & $\begin{array}{r}16 / 155 \\
8 / 102\end{array}$ & $0 \cdot 76$ & $0 \cdot 34,1 \cdot 71$ \\
\hline \multicolumn{9}{|l|}{ Income support } \\
\hline No & $12 \cdot 0$ & $14 / 117$ & 0.77 & $0 \cdot 36,1 \cdot 65$ & $7 \cdot 0$ & $9 / 129$ & $1 \cdot 41$ & $0 \cdot 62,3 \cdot 23$ \\
\hline Yes & $9 \cdot 2$ & 10/109 & & & $9 \cdot 8$ & 12/122 & & \\
\hline \multicolumn{9}{|l|}{ Housing type } \\
\hline Public & $11 \cdot 8$ & 19/161 & $1 \cdot 16$ & $0 \cdot 46,2 \cdot 94$ & $7 \cdot 4$ & $13 / 176$ & $0 \cdot 61$ & $0 \cdot 26,1 \cdot 46$ \\
\hline \multicolumn{8}{|c|}{ Extended family contact } & \\
\hline Daily/often & $10 \cdot 1$ & $20 / 199$ & 0.96 & $0.35,2.64$ & $8 \cdot 1$ & $18 / 221$ & 0.53 & $0 \cdot 22,1 \cdot 25$ \\
\hline Sometimes/never & $10 \cdot 5$ & $4 / 38$ & & & $15 \cdot 4$ & $6 / 39$ & & \\
\hline \multicolumn{9}{|c|}{ Traditional food intake (times/month) } \\
\hline$\geq 19$ & $8 \cdot 9$ & $11 / 124$ & 0.75 & $0 \cdot 35,1 \cdot 61$ & $6 \cdot 8$ & $9 / 133$ & 0.56 & $0 \cdot 26,1 \cdot 24$ \\
\hline$<19$ & $11 \cdot 8$ & $13 / 11$ & & & $12 \cdot 0$ & $15 / 125$ & & \\
\hline \multicolumn{9}{|c|}{ Treated for ear infection (past 12 months) } \\
\hline Yes & $10 \cdot 7$ & $8 / 75$ & $1 \cdot 10$ & $0 \cdot 49,2 \cdot 47$ & $14 \cdot 5$ & $12 / 83$ & $2 \cdot 20$ & $1 \cdot 01,4 \cdot 76^{\star}$ \\
\hline No & $9 \cdot 7$ & 15/154 & & & $6 \cdot 6$ & $11 / 167$ & & \\
\hline \multicolumn{9}{|c|}{ Breathing/respiratory illness (past 12 months) } \\
\hline Yes & $8 \cdot 3$ & $9 / 108$ & $0 \cdot 7$ & $0 \cdot 32,1 \cdot 54$ & $10 \cdot 4$ & $12 / 115$ & $1 \cdot 24$ & $0 \cdot 58,2 \cdot 64$ \\
\hline No & $11 \cdot 9$ & $15 / 126$ & & & $8 \cdot 5$ & 12/142 & & \\
\hline
\end{tabular}

${ }^{\star} P<0.05 ;{ }^{\star \star \star} P<0.001$

possible mechanisms involve bacterial damage to gastric glandular tissue and competition for iron in the stomach $^{(13,15,18,51-53)}$. In addition to the limitations explained above, perhaps the young age of the study group is relevant in explaining the lack of association between iron status and previous $H$. pylori exposure.

Although $10 \cdot 8-18 \cdot 0 \%$ prevalence of mild ID warrants continued public health attention, it is reassuring that the prevalence of IDA, the most severe form of ID, is low. However, apart from sex, we found no significant correlates of iron status in Inuit preschoolers in Nunavut. Iron absorption is one relevant issue that was not explored in the present study. It has been postulated that the Inuit may have adapted to excessive and deleterious iron intake through lowered iron absorption, which may now have implications for low iron stores given the nutrition transition away from iron-rich traditional foods ${ }^{(54)}$. However, little evidence is currently available to support or refute this hypothesis ${ }^{(16,54)}$.
Finally, in the present study, anaemia from all causes was found in $16 \cdot 8 \%$ of Inuit children and only $20-31 \%$ of this anaemia was explained by low iron status. Other studies in children and infants have shown similar results in which only a portion of the observed anaemia is explained by ID $^{(55-57)}$. Dietary causes of anaemia other than low iron intake include deficiencies in vitamin A, folate, vitamin $\mathrm{B}_{12}$ and riboflavin ${ }^{(58)}$. However, again, given the high meat and cereal intake noted, most of these micronutrient deficiencies are unlikely. Vitamin A deficiency could be evaluated in future research given that an earlier study found that young Inuit adults had a greater likelihood of having a retinol activity equivalent falling below the EAR than older Inuit adults, attributed to the changing pattern of traditional food consumption by age ${ }^{(59)}$. However, in analyses of the present study population, the majority of children had a vitamin A intake above the $\mathrm{EAR}^{(28)}$. 
Anaemia not attributable to ID could be related to acute inflammation. In acute infection, inflammation reduces erythrocyte half-life and the acute phase response blocks iron export proteins trapping iron inside cells ${ }^{(60-62)}$. Interestingly, we found that children who required treatment for an ear infection in the past year, when compared to those who did not, had a significantly greater risk for being anaemic. Ear and respiratory infections are common among Inuit children ${ }^{(63,64)}$. One hypothesis is that recurring infections during childhood may result in mild anaemia, although the reverse may also occur, where anaemia may increase the risk of infection ${ }^{(65,66)}$. We also found that household crowding significantly predicted anaemia. Household crowding is a relevant health indicator for young children who spend the majority of their time at home with increased risk for person-to-person spread of infections ${ }^{(63,67-69)}$.

\section{Limitations}

Owing to the rarity of IDA in this population, our study was underpowered to detect significant correlates. The crosssectional design prevents exploration of causal relationships between correlates and ID, IDA and anaemia.

\section{Conclusion}

Inuit children aged 3-5 years have higher rates of ID, IDA and anaemia than non-aboriginal children. The rates observed, however, were not excessively high and do not warrant immediate intervention. The present study also revealed that ID explains only $20-31 \%$ of low $\mathrm{Hb}$ and that anaemia was generally mild. The role of household crowding, history of infections and age need to be evaluated for their role in exacerbating anaemia. The study found that Inuit preschoolers have iron intake levels that are most likely adequate for their age, which is an important positive finding for children likely to be exposed to rapid nutrition transition in the Arctic. Health promotion efforts are best placed at encouraging beneficial dietary behaviours that already exist in Nunavut's communities and in extending these beneficial behaviours in efforts targeting high-risk women of reproductive age and infants. Caregivers should be commended for feeding preschoolers many different iron-rich foods, especially iron-rich traditional meats, and encouraged and supported to continue these practices while reducing intake of foods that are less nutrient-rich but contribute to high energy intake.

\section{Acknowledgements}

Funding for the present study was provided through the Government of Canada International Polar Year, the Canadian Institutes for Health Research, Indian and Northern Affairs Canada and Health Canada. There are no conflicts of interest to declare. A.P. facilitated the collection of field data, conducted background research, performed data analyses and drafted the manuscript. H.W. helped with lab analyses and data interpretation and with final editing of the manuscript. G.M.E. was the principal investigator of the Nunavut Inuit Child Health Survey; she developed the content and design of the survey as well as guided the statistical analyses, interpreted the results and reviewed and edited the manuscript. All authors have approved the final version submitted for review. The authors would like to acknowledge the Nunavut Inuit Health Survey Steering Committee and extend a special thanks to Laureen Pameolik, Kathy Morgan, Christine Ekidliak and Nancy Faraj for field survey work and to Louise Johnson-Down for assistance with dietary intake analyses and quality control.

\section{References}

1. Beard JL (2001) Iron biology in immune function, muscle metabolism and neuronal functioning. J Nutr 131, 2 Suppl. 2, S568-S580.

2. World Health Organization, United Nations University \& United Nations Children's Fund (2001) Iron Deficiency Anaemia Assessment, Prevention and Control: A Guide for Programme Managers. Geneva: WHO.

3. Yip R (1994) Iron deficiency: contemporary scientific issues and international programmatic approaches. J Nutr 124, 8 Suppl., S1479-S1490.

4. Gibson R (2005) Principles of Nutritional Assessment. New York: Oxford University Press.

5. Statistics Canada (2007) 2006 Census Dictionary: 'Aboriginal Identity'. http://www12.statcan.ca/census-recensement/2006/ ref/dict/pop001-eng.cfm (accessed November 2008).

6. Christofides A, Schauer C \& Zlotkin SH (2005) Iron deficiency and anemia prevalence and associated etiologic risk factors in First Nations and Inuit communities in Northern Ontario and Nunavut. Can J Public Health 96, 304-307.

7. Willows ND, Dewailly E \& Gray-Donald K (2000) Anemia and iron status in Inuit infants from northern Quebec. Can J Public Health 91, 407-410.

8. Zlotkin SH, Ste-Marie M, Kopelman H et al. (1996) The prevalence of iron depletion and iron-deficiency anaemia in a randomly selected group of infants from four Canadian cities. Nutr Res 16, 729-733.

9. Nutrition Canada (1975) Nutrition Canada: The Eskimo Survey Report: A Report from Nutrition Canada by the Bureau of Nutritional Sciences, Health Protection Branch, Department of National Health and Welfare. Ottawa: Nutrition Canada.

10. Centers for Disease Control and Prevention (1999) Iron deficiency anemia in Alaskan native children - Hooper Bay, Alaska. MMWR 48, 714-716.

11. Kuhnlein HV \& Receveur O (2007) Local cultural animal food contributes high levels of nutrients for Arctic Canadian Indigenous adults and children. J Nutr 137, 1110-1114.

12. Young TK, Moffat M, O'Neil JD et al. (1995) The population survey as a tool for assessing family health in the Keewatin region, NWT, Canada. Arctic Med Res 54, Suppl. 1, 77-85.

13. Annibale B, Capurso G, Lahner E et al. (2003) Concomitant alterations in intragastric $\mathrm{pH}$ and ascorbic acid concentration in patients with Helicobacter pylori gastritis and associated iron deficiency anaemia. Gut 52, 496-501.

14. Annibale B, Marignani M, Monarca B et al. (1991) Reversal of iron deficiency anemia after Helicobacter pylori eradication 
in patients with asymptomatic gastritis. Ann Intern Med 131, 668-672.

15. Ashorn M (2004) Acid and iron-disturbances related to Helicobacter pylori infection. I Pediatr Gastroenterol Nutr 38, 137-139.

16. Baggett HC, Parkinson AJ, Muth PT et al. (2006) Endemic iron deficiency associated with Helicobacter pylori infection among school-aged children in Alaska. Pediatrics 117, 396-404.

17. Barabino A (2002) Helicobacter pylori-related iron deficiency anemia: a review. Helicobacter 7, 71-75.

18. Baysoy G, Ertem D, Ademolu E et al. (2004) Gastric histopathology, iron status and iron deficiency anemia in children with Helicobacter pylori infection. I Pediatr Gastroenterol Nutr 38, 146-151.

19. Cardenas VM, Mulla ZD, Ortiz M et al. (2006) Iron deficiency and Helicobacter pylori infection in the United States. Am J Epidemiol 163, 127-134.

20. Carnicer J, Badia R \& Argemi J (1997) Helicobacter pylori gastritis and sideropenic refractory anemia. I Pediatr Gastroenterol Nutr 25, 441.

21. Dufour C, Brisigotti M, Fabretti G et al. (1993) Helicobacter pylori gastric infection and sideropenic refractory anemia. J Pediatr Gastroenterol Nutr 17, 225-227.

22. Konno M, Muraoka S, Takahashi M et al. (2000) Iron deficiency anemia associated with Helicobacter pylori gastritis. I Pediatr Gastroenterol Nutr 31, 52-56.

23. Kostaki M, Fessatou S \& Karpathios T (2003) Refractory iron-deficiency anaemia due to silent Helicobacter pylori gastritis in children. Eur J Pediatr 162, 177-179.

24. Bernstein C, McKeown I, Embil J et al. (1999) Seroprevalence of Helicobacter pylori, incidence of gastric cancer, and peptic ulcer-associated hospitalizations in a Canadian Indian Population. Dig Dis Sci 44, 668-674.

25. Sinha S, Martin B, Sargent M et al. (2002) Age at acquisition of Helicobacter pylori in a pediatric Canadian First Nations population. Helicobacter 7, 76-85.

26. Egeland GM, Pacey A, Cao Z et al. (2010) Food insecurity among Inuit preschoolers: Nunavut Inuit Child Health Survey, 2007-2008. CMAJ 182, 243-248.

27. Galloway T, Young TK \& Egeland GM (2010) Emerging obesity among preschool-aged Canadian Inuit Children: results from the Nunavut Inuit Child Health Survey. Int $J$ Circumpolar Health 69, 151-157.

28. Johnson-Down L \& Egeland GM (2010) Adequate nutrient intakes are associated with traditional food consumption in Nunavut Inuit children aged 3-5 years. $J$ Nutr $\mathbf{1 4 0 ,}$ 1311-1316.

29. Kuczmarski RJ, Ogden CL, Guo SS et al. (2002) 2000 CDC Growth Charts for the United States: methods and development. Vital Health Stat 11 246, 1-190.

30. Looker AC, Dallman PR, Carroll MD et al. (1997) Prevalence of iron deficiency in the United States. JAMA 277, 973-976.

31. Beard JL, Murray-Kolb LE, Rosales FJ et al. (2006) Interpretation of serum ferritin concentrations as indicators of total-body iron stores in survey populations: the role of biomarkers for the acute phase response. Am J Clin Nutr 84, 1498-1505.

32. Wander K, Shell-Duncan B \& McDade TW (2009) Evaluation of iron deficiency as a nutritional adaptation to infectious disease: an evolutionary medicine perspective. Am J Hum Biol 21, 172-179.

33. Lawn J \& Harvey D (2003) Nutrition and Food Security in Kugaaruk, Nunavut: Baseline Survey for the Food Mail Pilot Project. Ottawa: Ministry of Indian Affairs and Northern Development.

34. United States Department of Agriculture (2007) Food Security in the United States: Measuring Household Food Security. http://www.ers.usda.gov/Briefing/FoodSecurity/ measurement.htm (accessed January 2008).
35. Institute of Medicine (2000) Dietary Reference Intakes: Applications in Dietary Assessment. Washington, DC: National Academy Press.

36. World Health Organization, Centers for Disease Control and Prevention (2004) Assessing the Iron Status of Populations: Technical Consultation on the Assessment of Iron Status at the Population Level. Geneva: WHO.

37. Canadian Community Health Survey. Cycle 2.2, nutrition (2004) Nutrient intakes from food. Provincial, regional and national summary data tables, vol. 1. http://www.hc-sc.gc.ca/ fn-an/alt_formats/hpfb-dgpsa/pdf/surveill/cc_tab13-eng.pdf (accessed June 2010).

38. Kuhnlein H, Soueida R \& Receveur O (1996) Dietary nutrient profiles of Canadian Baffin Island Inuit differ by food source, season, and age. J Am Diet Assoc 96, 155-162.

39. Moshfegh A, Goldman J \& Cleveland L (2005) What We Eat in America, NHANES 2001-2002: Usual Nutrient Intakes from Food Compared to Dietary Reference Intakes. Washington, DC: USDA, Agricultural Research Service; available at http://www.ars.usda.gov/Services/docs.htm? docid $=13793$

40. Brotanek JM, Gosz J, Weitzman M et al. (2007) Iron deficiency in early childhood in the United States: risk factors and racial/ ethnic disparities. Pediatrics 120, 568-575.

41. Moayeri H, Bidad K, Zadhoush S et al. (2006) Increasing prevalence of iron deficiency in overweight and obese children and adolescents (Tehran Adolescent Obesity Study). Eur J Pediatr 165, 813-814.

42. Nead KG, Halterman JS, Kaczorowski JM et al. (2004) Overweight children and adolescents: a risk group for iron deficiency. Pediatrics 114, 104-108.

43. Pinhas-Hamiel O, Newfield RS, Koren I et al. (2003) Greater prevalence of iron deficiency in overweight and obese children and adolescents. Int J Obes Relat Metab Disord 27, 416-418.

44. Zimmermann MB, Zeder C, Muthayya S et al. (2008) Adiposity in women and children from transition countries predicts decreased iron absorption, iron deficiency and a reduced response to iron fortification. Int J Obes (Lond) 32, 1098-1104.

45. Parkinson AJ, Gold BD, Bulkow L et al. (2000) High prevalence of Helicobacter pylori in the Alaska native population and association with low serum ferritin levels in young adults. Clin Diagn Lab Immunol 7, 885-888.

46. Segal I, Otley A, Issenman R et al. (2008) Low prevalence of Helicobacter pylori infection in Canadian children: a crosssectional analysis. Can J Gastroenterol 22, 485-489.

47. Malaty HM, Haveman T, Graham DY et al. (2002) Helicobacter pylori infection in asymptomatic children: impact of epidemiologic factors on accuracy of diagnostic tests. J Pediatr Gastroenterol Nutr 35, 59-63.

48. Oderda G, Rapa A \& Bona G (2004) Diagnostic tests for childhood Helicobacter pylori infection: invasive, noninvasive or both? J Pediatr Gastroenterol Nutr 39, 482-484.

49. Okuda M, Miyashiro E, Koike M et al. (2002) Serodiagnosis of Helicobacter pylori infection is not accurate for children aged below 10. Pediatr Int 44, 387-390.

50. Barabino A, Dufour C, Marino CE et al. (1999) Unexplained refractory iron-deficiency anemia associated with Helicobacter pylori gastric infection in children: further clinical evidence. I Pediatr Gastroenterol Nutr 28, 116-119.

51. Dhaenens L, Szczebara F \& Husson M (1997) Identification, characterization and immunogenicity of the lactoferrinbinding protein from Helicobacter pylori. Infect Immun $\mathbf{6 5}$, 514-518.

52. Husson M, Legrand D, Spick G et al. (1993) Iron acquisition by Helicobacter pylori: importance of human lactoferrin. Infect Immun 61, 2694-2697.

53. Sarker SA, Davidsson L, Mahmud H et al. (2004) Helicobacter pylori infection, iron absorption, and gastric acid secretion in Bangladeshi children. Am J Clin Nutr 80, 149-153. 
54. Gessner BD (2009) Geographic and racial patterns of anemia prevalence among low-income Alaskan children and pregnant or postpartum women limit potential etiologies. J Pediatr Gastroenterol 48, 475-481.

55. Gamble MV, Palafox NA, Dancheck B et al. (2004) Relationship of vitamin A deficiency, iron deficiency, and inflammation to anemia among preschool children in the Republic of the Marshall Islands. Eur J Clin Nutr 58, 1396-1401

56. Thurlow RA, Winichagoon P, Green T et al. (2005) Only a small proportion of anemia in northeast Thai schoolchildren is associated with iron deficiency. Am J Clin Nutr 82, 380-387.

57. White KC (2005) Anemia is a poor predictor of iron deficiency among toddlers in the United States: for heme the bell tolls. Pediatrics 115, 315-320.

58. Fishman SM, Christian P \& West KP (2000) The role of vitamins in the prevention and control of anaemia. Public Health Nutr 3, 125-150.

59. Egeland G, Berti P, Soueida R et al. (2004) Age differences in vitamin A intake among Canadian Inuit. Can J Public Health 95, 465-469.

60. Abshire TC \& Reeves JD (1983) Anemia of acute inflammation in children. J Pediatr 103, 868-871.

61. Seitz RC, Buschermöhle G, Dubberke G et al. (1993) The acute infection-associated hemolytic anemia of childhood: immunofluorescent detection of microbial antigens altering the erythrocyte membrane. Ann Hematol 67, 191-196.

62. Weiss G (2008) Iron metabolism in the anemia of chronic disease. Biochim Biophys Acta 1790, 682-693.

63. Banerji A, Bell A, Mills EL et al. (2001) Lower respiratory tract infections in Inuit infants on Baffin Island. CMAJ 164, 1847-1850.

64. Alaghehbandan R, Gates KD \& MacDonald D (2007) Hospitalization due to pneumonia among Innu, Inuit and non-Aboriginal communities, Newfoundland and Labrador, Canada. Int J Infect Dis 11, 23-28.

65. Walter T, Olivares M, Pizarro F et al. (1997) Iron, anemia, and infection. Nutr Rev 55, 111-124.

66. Levy A, Fraser D, Rosen SD et al. (2005) Anemia as a risk factor for infectious diseases in infants and toddlers: results from a prospective study. Eur J Epidemiol 20, 277-284.

67. Baker MF, McNicholas A, Garrett N et al. (2000) Household crowding a major risk factor for epidemic meningococcal disease in Auckland children. Pediatr Infect Dis J 19, 983-990.

68. Bulkow LR, Singleton RJ, Karron RA et al., The Alaska RSV Study Group (2002) Risk factors for severe respiratory syncytial virus infection among Alaska Native children. Pediatrics 109, 210-216.

69. Kovesi T, Stocco C, Fugler D et al. (2007) Indoor air quality and the risk of lower respiratory tract infections in young Canadian Inuit children. CMAJ 177, 155-160. 